\title{
CORRELATION OF NON-HIGH-DENSITY LIPOPROTEIN CHOLESTEROL WITH LIPOPROTEIN(A) IN DIABETIC PATIENTS
}

\author{
VASANTHAN M* \\ Department of Biochemistry, SRM Medical College Hospital and Research Centre, SRM Institute, Kattankulathur, Kanchipuram, \\ Tamil Nadu, India. Email: vasanthan.doc@gmail.com
}

Received: 27 March 2018, Revised and Accepted: 08 August 2018

\section{ABSTRACT}

Objective: The objective of this study is to estimate the level of lipoprotein(a) and lipid profile, especially non-high-density lipoprotein cholesterol (non-HDL-C) in diabetic patients, and to correlate the same with healthy controls (non-diabetics).

Methods: A total of 30 non-diabetic subjects and 30 diabetic patients were included in the study. Lipoprotein(a) (Lp[a]) was estimated by immunoturbidimetry and the other parameters by their respective methods in biochemistry auto-analyzer.

Result: From the study, it was found that both $\mathrm{Lp}(\mathrm{a})$ and non-HDLC were increased in diabetics when compared to the non-diabetic controls. It was also evident that there is a positive correlation of $\mathrm{Lp}(\mathrm{a})$ levels with non-HDL C.

Conclusion: Lp(a) and non-HDL C are responsible for atherogenic events in uncontrolled diabetic patients, leading to risks such as coronary artery disease.

Keywords: Lipoprotein(a), Non-high-density lipoprotein, Coronary artery disease.

(C) 2018 The Authors. Published by Innovare Academic Sciences Pvt Ltd. This is an open access article under the CC BY license (http://creativecommons. org/licenses/by/4. 0/) DOI: http://dx.doi.org/10.22159/ajpcr.2018.v11i9.26278

\section{INTRODUCTION}

According to the World Health Organization, " The term diabetes mellitus (DM) describes a metabolic disorder of multiple etiologies characterized by chronic hyperglycemia with disturbances of carbohydrate, fat, and protein metabolism resulting from defects in insulin secretion, insulin action, or both."

Low-density lipoprotein-cholesterol (LDL-C) till now is being considered as the most important analyte in cardiovascular prevention. Treatment modalities are most often based on lowering the LDL-C. However, along with LDL-C, very LDL (VLDL-C) and the so-called remnant lipoproteins are also atherogenic.

Hence, the need for an individual alternative analyte that would reflect all of the atherogenic particles is justified. This is better understood by calculating the non-high-density lipoprotein C (non-HDL-C) concentration.

According to a study conducted in South India by Kumpatla et al. [1], nonHDL-C is the most common lipid abnormality among Type 2 DM (T2DM) patients in patients with coronary artery disease with a prevalence of $21.6 \%$ among patients who were already on lipid-lowering agents (Statins) and with normal LDL-C levels. With normal LDL-C levels, 47\% of the T2DM patients with CV events had elevated non-HDL-C. The study, hence, tells us the importance of conducting more studies on non-HDL-C as a unique risk predictor of diabetic complications.

Lipoprotein(a) (Lp[a]) is a lipoprotein subclass, rich in cholesterol, and was first described by Berg in 1963 [2]. Lp(a) contains a LDL C particle which is attached to apolipoprotein(a) and a glycoprotein [3,4] and acts as an atherogenic factor as well.

The main objective of the study is to estimate the level of Lp(a) and lipid profile, especially non-HDL C in diabetic patients, and to correlate the same with healthy controls (non-diabetics).

\section{MATERIALS AND METHODS}

A total of 60 patients attending a private medical college and hospital at Chennai participated in the study were selected.

Study individuals were divided into two groups.

Group A - 30 age- and sex-matched healthy non-diabetic controls with hemoglobin A1c (HbA1c) $<5.6 \%$. The samples of both the groups were

Table 1: Methods of estimation

\begin{tabular}{ll}
\hline Parameter & Method \\
\hline Lp (a) & Immunoturbidimetry \\
Total cholesterol & Cholesterol oxidase-peroxidase \\
HDL-C & Direct antibody inhibition \\
\hline
\end{tabular}

Non-HDL-C was calculated using the formula: Non-HDL-C: Total

cholesterol- HDL cholesterol. Non-HDL-C: Non-high density lipoprotein cholesterol, Lp (a): Lipoprotein (a)

Table 2: Lp (a) and non-HDL among Group A

\begin{tabular}{lllll}
\hline Parameter & n & Minimum & Maximum & Mean \pm SD \\
\hline Lp (a) mg/dl & 30 & 8.1 & 12.6 & $10.29 \pm 1.288$ \\
Non-HDL-C mg/dl & 30 & 56 & 157 & $111.83 \pm 26.621$ \\
\hline Non-HDL-C: Non-high-density lipoprotein cholesterol, Lp (a): Lipoprotein (a),
\end{tabular}

SD: Standard deviation

Table 3: Lp (a) and non-HDL among Group B

\begin{tabular}{lllll}
\hline Parameter & n & Minimum & Maximum & Mean \pm SD \\
\hline Lp (a) mg/dl & 30 & 14.9 & 28.6 & $22.12 \pm 4.3154$ \\
Non-HDL-C mg/dl & 30 & 153 & 263 & $207.73 \pm 29.027$ \\
\hline
\end{tabular}

Non-HDL-C: Non-high-density lipoprotein cholesterol, Lp (a): Lipoprotein (a), SD: Standard deviation 
Table 4: Student's t-test

\begin{tabular}{|c|c|c|c|c|c|c|c|}
\hline \multirow[t]{2}{*}{ Dependent variable } & \multirow[t]{2}{*}{ Group } & \multirow[t]{2}{*}{ Group } & \multirow[t]{2}{*}{ Mean difference (AB) } & \multirow[t]{2}{*}{ Standard error } & \multirow[t]{2}{*}{ Significance } & \multicolumn{2}{|c|}{$95 \%$ confidence interval } \\
\hline & & & & & & Lower bound & Upper bound \\
\hline Lp (a) & $\mathrm{A}$ & B & $-11.83^{*}$ & 0.822 & $<0.0001$ & -13.476 & -10.184 \\
\hline
\end{tabular}

*The mean difference is significant at the 0.05 level. Non-HDL-C: Non-high-density lipoprotein cholesterol, Lp (a): Lipoprotein (a)

collected and estimated for certain parameters by their respective methods (Table 1).

Group B - 30 diabetic patients with HbA1c 8-9\% and of age group 4050 years.

After the approval by the Institutional Research and Ethical Committee, written informed consent was obtained from all the participants enrolled. Demographic data, age, gender, duration of diabetes, general history, and medications were recorded. Fasting blood samples were collected. The concentrations of Lp(a), total cholesterol, and HDL-C were measured (Tables 2,3).

Patients with estrogen depletion and hypothyroidism were excluded from the study.

\section{RESULTS}

The study population comprised of a total of 60 individuals, and of these, Group A was 30 healthy controls and Group-B was 30 diabetics.

The biochemical study parameters were analyzed with the help of Statistical Product and Service Solutions 22 software.

To find the difference in group means and statistical significance, Student's t-test was used.

The results obtained clearly show an increased concentration of the parameters Lp(a) and non-HDL-C in Group B (diabetic patients) when compared to the healthy controls, with a significance of $\mathrm{p}<0.05$ (Table 4).

\section{DISCUSSION}

The study was done on diabetic patients. Between the study group and the control group, both $\mathrm{Lp}(\mathrm{a})$ and non-HDL-C levels differed significantly.

The atherogenic property of $\operatorname{Lp}(\mathrm{a})$ is illustrated by its capacity to bind with fibronectin in a study conducted by Salonen et al. [5]. Lp(a) inhibits binding of plasminogen to the cell surface by accumulating in the vessel wall. This, in turn, reduces the plasmin generation, thereby increasing the clot formation and promoting proliferation of smooth muscle cells. There are other studies conducted worldwide showing the significantly high Lp(a) among renal patients and also the early possibilities of coronary heart diseases development because of the proatherogenic effect of the increased Lp(a) [4-9] supporting our study.

Furthermore, there are various studies conducted worldwide which shows non-HDL-C as the potent marker in risk factor evaluation of atherosclerosis [10-13] and eventually coronary artery disease [14-17].

According to a study conducted in Malaysia, lipid abnormalities are frequently found in diabetes patients and are associated with increased risk of CHD [18].

The study conducted by Nayak and Bhaktha. shows important difference among biochemical parameters and other risk factors in the Asian phenotypic races with countries such as India and Trinidad. The data also showed that Indian diabetic population is at higher risk of developing complications when compared to Trinidadians [19].
These studies clearly depict the importance of $\mathrm{Lp}(\mathrm{a})$ and non-HDL-C as independent parameters and the study conducted by us reveals that the duo can act as combined parameters in routine diabetic profile biochemical investigations would help in predicting the diabetic complications in a better way among the Indian population.

\section{CONCLUSION}

The results of this study and previous studies provide ample evidence that $\operatorname{Lp}(\mathrm{a})$ and Non-HDL-C levels are increased in diabetics compared to the normal $\mathrm{Lp}(\mathrm{a})$ and non-HDL-C levels in non-diabetic controls. The present study observed that there is a positive correlation of $\mathrm{Lp}(\mathrm{a})$ concentration and Non -HDL-C concentration with the patients with $\mathrm{DM}$, proving their role in diabetic complications such as coronary artery disease and chronic renal failure.

\section{AUTHOR'S CONTRIBUTION}

I declare that I, the author has made substantial contributions to conception and design, acquisition, analysis, and interpretation of data. The author has also participated in drafting and revising the article and given his approval for submission and intellectual content.

\section{ETHICAL STANDARDS}

All procedures performed in the study involving human participants were in accordance with the ethical standards of the institution (Ref. No. 002/SBMCH/IHEC/2013-056). Informed consent was obtained from all individual participants included in the study.

\section{CONFLICTS OF INTEREST}

The author declared that they had no conflicts of interest.

\section{REFERENCES}

1. Kumpatla S, Soni A, Narasingan SN, Viswanathan V. Presence of elevated non-HDL among patients with T2DM with CV events despite of optimal LDL-C - A report from South India. Indian Heart J 2016;68:378-9.

2. Berg K. A new serum type system in man - The Lp system. Acta Pathol Microbiol Scand 1963;59:369-82.

3. Mbewu AD, Durrington PN. Lipoprotein (a): Structure and possible involvement in thrombogenesis and atherosclerosis. Atherosclerosis 1999;85:1-14.

4. Kamstrip PR, Nordestgard BG. Extreme lipoprotein(a) levels and myocardial infarction. Circulation 2008;117:176-84.

5. Salonen EM, Jauhiainen M, Zardi L, Vaheri A, Ehnholm C. Lipoprotein(a) binds to fibronectin and has serine proteinase activity capable of cleaving it. EMBO J 1989;8:4035-40.

6. Nordestgaard BG, Chapman MJ, Ray K, Borén J, Andreotti F, Watts GF, et al. Lipoprotein(a) as a cardiovascular risk factor: Current status. Eur Heart J 2010;31:2844-53.

7. Kamstrup PR, Tybjærg-Hansen A, Nordestgaard BG. Lipoprotein(a) and risk of myocardial infarction - genetic epidemiologic evidence of causality. Scand J Clin Lab Invest 2011;71:87-93.

8. Danesh J, Collins R, Peto R. Lipoprotein(a) and coronary heart disease. Meta-analysis of prospective studies. Circulation 2000;102:1082-5.

9. Smolders B, Lemmens R, Thijs V. Lipoprotein (a) and stroke: A metaanalysis of observational studies. Stroke 2007;38:1959-66.

10. Schreiner PJ, Morrisett JD, Sharrett AR, Patsch W, Tyroler HA, Wu K, et al. Lipoprotein[a] as a risk factor for preclinical atherosclerosis. Arterioscler Thromb 1993;13:826-33

11. Shimano H, Arai H, Harada-Shiba M, Ueshima H, Ohta T, Yamashita S, 
et al. Proposed guidelines for hypertriglyceridemia in japan with non-HDL cholesterol as the second target. J Atheroscler Thromb 2008;15:116-21.

12. Frontini MG, Srinivasan SR, Xu J, Tang R, Bond MG, Berenson GS. Usefulness of childhood non-high-density lipoprotein cholesterol levels versus other lipoprotein measures in predicting adult subclinical atherosclerosis: The Bogalusa heart study. Pediatrics 2008;121:24-9.

13. Kawamoto R, Oka Y, Tomita H, Kodama A. Non-HDL cholesterol as a predictor of carotid atherosclerosis in the elderly. J Atheroscler Thromb 2005;12:143-8.

14. Orakzai SH, Nasir K, Blaha M, Blumenthal RS, Raggi P. Non-HDL cholesterol is strongly associated with coronary artery calcification in asymptomatic individuals. Atherosclerosis 2009;202:289-95.

15. Liu J, Sempos C, Donahue RP, Dorn J, Trevisan M, Grundy SM, et al. Joint distribution of non-HDL and LDL cholesterol and coronary heart disease risk prediction among individuals with and without diabetes. Diabetes Care 2005;28:1916-21.

16. Pischon T, Girman CJ, Sacks FM, Rifai N, Stampfer MJ, Rimm EB, et al. Non-high-density lipoprotein cholesterol and apolipoprotein B in the prediction of coronary heart disease in men. Circulation 2005;112:3375-83.

17. Chien KL, Hsu HC, Su TC, Chen MF, Lee YT, Hu FB, et al. Apolipoprotein B and non-high density lipoprotein cholesterol and the risk of coronary heart disease in Chinese. J Lipid Res 2007;48:2499-505.

18. Butt M, Ali AM, Bakry MM. Lipid profile patterns and association between glycated hemoglobin (HbA1C) and atherogenic index of plasma (AIP) in diabetes patients at a tertiary care hospital in Malaysia. Int J Pharm Pharm Sci 2017;9:150-4.

19. Nayak BS, Bhaktha G. Inconsistent lipid profiles exhibited among the diabetic Asian Indians of India and Trinidad-a comparative study. Int J Pharm Pharm Sci 2016;8:60-3. 